\title{
Aberrant Reduction of MiR-141 Increased CD47/CUL3 in Hirschsprung's Disease
}

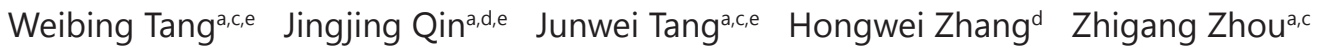 \\ Bo Li,c Qiming Geng ${ }^{\mathrm{c}}$ Wei Wu ${ }^{\mathrm{a}, \mathrm{b}}$ Yankai Xia ${ }^{\mathrm{a}, \mathrm{b}}$ Xiaoqun Xu $\mathrm{u}^{\mathrm{a}, \mathrm{c}}$ \\ aState Key Laboratory of Reproductive Medicine, Institute of Toxicology, School of Public Health, \\ Nanjing Medical University, ${ }^{b}$ Key Laboratory of Modern Toxicology (Nanjing Medical University), \\ Ministry of Education, 'Department of Pediatric Surgery, Nanjing Children's Hospital Affiliated Nanjing \\ Medical University, Nanjing, 'Department of Pediatric Surgery, Xuzhou Children's Hospital Affiliated

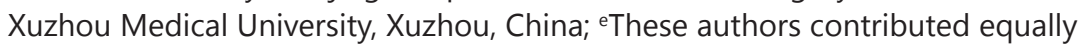

\section{Key Words}

miR-141 • Hirschsprung's disease • Methylation • Migration • Proliferation

\begin{abstract}
Background: MiR-141 has been confirmed to be associated with various human diseases. However, whether miR-141 is involved in the pathogenesis of Hirschsprung's disease (HSCR) remains unknown. Here, we design the experiment to reveal the relationship between miR141 and HSCR. Methods: Quantitative real-time PCR and Western blot were used to detect the expression levels of miR-141 and its potential genes in 70 tissues of HSCR compared with 60 controls. Bisulfite sequencing PCR (BSP) assay was applied to explain the possible mechanism of the aberrant expression level of miR-141. We employed a dual-luciferase reporter assay to validate the regulation relation between miR-141 and CD47/CUL3. Cell migration, proliferation, apoptosis, and cell cycle progression were examined by transwell assay, MTT assay, and flow cytometry, respectively. Results: MiR-141 was down-regulated whereas CD47 and CUL3 expression was increased in colon tissues from patients with HSCR compared with control group, The increased level of CD47 and CUL3 induced by miR-141 reduced proliferation and migration of $293 \mathrm{~T}$ and SH-SY5Y cells. Furthermore, this suppression was reversed by reducing of CD47 and CUL3. Hypermethylation of a CpG Island in the promoter region of miR-141 gene was confirmed in HSCR tissues. Conclusion: Aberrant reduction of miR-141 may play an important role in the pathogenesis of HSCR with the inhibiting affection on cell migration and proliferation abilities. The present study demonstrates for the first time the role of miR-141 and its target genes in the occurrence of HSCR, and provides us a new direction for the study of the pathogenesis of Hirschsprung's disease.
\end{abstract}


\begin{tabular}{cl|l} 
Cellular Physiology & \multicolumn{2}{c}{ Cell Physiol Biochem 2013;32:1655-1667 } \\
\cline { 2 - 3 } and Biochemistry 10.1159/000356601 & $\begin{array}{l}\text { D 2013 S. Karger AG, Basel } \\
\text { www.karger.com/cpb }\end{array}$ \\
\cline { 2 - 3 } & Publisned onine: vecember 05, 2013 &
\end{tabular}

Tang et al.: miR-141 in Hirschsprung's Disease

\section{Introduction}

MicroRNAs(MiRNAs) are small, non-coding RNA molecules that are about 19-25 nucleotides long [1]. They could regulate target genes by triggering mRNA degradation or translational repression through complementary binding to the 3'-untranslated regions of target mRNAs [2]. MiR-141, a member of the miR-200 family, was highly associated with various human diseases especially malignancies such as gastric cancer, colon cancer, prostate and pancreatic cancer [3]. Extensive research found that miR-141 was involved in various diseases by affecting cell biological processes such as cell proliferation, migration, survival, and cell cycle or apoptosis through regulating its target genes [4]. However, whether miR141 is involved in HSCR still remains unknown. A deeper understanding of miRNAs during enteric nerve system development which may induce HSCR is very necessary.

Hirschsprung's disease (HSCR) is a common congenital disease in newborns. In live births, the incidence of this disease is about 1:2000-1:5000, while males are affected 4 times more often than females [5]. It is characterized that the migration of the enteric neural crest cells (ENCCs) stopped and failed to get to the hindgut during embryogenesis from 5 to 12 weeks, which caused the absence of ganglia cells in the intramural and submucosal along variable lengths of gastrointestinal tract [6]. The etiology studies of HSCR have shown that it is a complicated procedure in disease development, including genetic factors and environmental factors [7]. To date, more than 10 genes have been identified to be associated with the pathogenesis of HSCR [8]. However, whether miRNAs are involved in HSCR has not been reported.

This study was focused on miR-141 and was to explore its potential biological characteristics in the pathogenesis of Hirschsprung's disease.

\section{Materials and Methods}

\section{Patients and tissues samples}

This study was approved by the Institutional Ethics Committee of Nanjing Medical University. In the study, all activities involving subjects were done under compliance with the government policies and the Helsinki Declaration. A total of 70 HSCR colon tissue specimens were obtained from HSCR patients acquired surgical treatment in Nanjing Children's Hospital affiliated to Nanjing Medical University from October 2009 to May 2012 (NJMU Birth Cohort). All the patients were diagnosed by barium enema and anorectal manometry evaluation before surgical procedures. After surgery, pathological detection was performed to make a definite diagnosis. All the colon tissues collected in our research, the absence of ganglion cells was confirmed. 60 control colon tissues without the ischemia or necrosis parts were obtained from isolated patients received surgical treatment because of intussusception or incarcerated and strangulated inguinal hernia, and these patients were proved without HSCR or other congenital malformation. All of Children's guardians were provided informed consent for the use of the tissues before surgery. After surgical removal, the tissues were immediately frozen and stored at $-80{ }^{\circ} \mathrm{C}$.

\section{The prediction of potential target genes of miR-141}

Three database including miRGen (http://www.diana.pcbi.upenn.edu/miRGen/v3/miRGen. html), PicTar (http://pictar.mdc-berlin.de/) and TargetScan (http://www.targetscan.org) were used to predict the potential target genes of miR-141.

\section{Quantitative RT-PCR}

Total RNAs were extracted from tissues using Trizol reagent (Invitrogen Life Technologies Co, CA, USA) according to the protocol of the manufactory. The cDNA synthesis used for miR-141 quantitation was carried out with TaqMan MicroRNA RT Kit (Applied Biosystems, CA, USA). And TaqMan ${ }^{\circledR}$ MicroRNA Assay (Applied Biosystems, CA, USA) was used as the probe. Hsa-U6 snRNA was acted as a normalized control. 


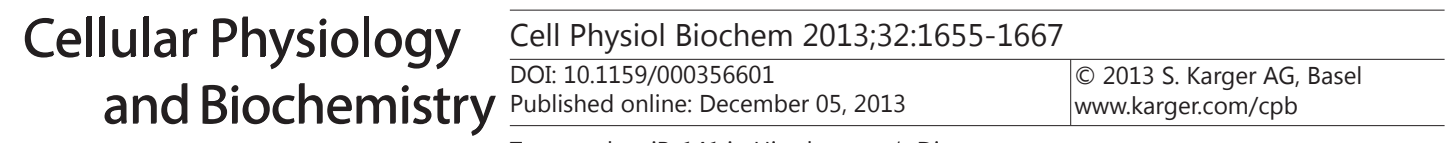

Tang et al.: miR-141 in Hirschsprung's Disease

Table 1. Sequences of primers for ATNX1,IRS2,CD47,CHD9 and CUL3,B-action

\begin{tabular}{lc}
\hline B-actin & Forward 5'-CCAACCGCGAGAAGATGA-3' \\
& Reverse 5'-CCAGAGGCGTACAGGGATAG-3' \\
ATNX1 & Forward 5'- TCGGTGGAGCTTGGTTTACAA-3' \\
& Reverse 5'- GGGAGGACCCAATGAACTGG-3' \\
IRS2 & Forward 5' - CGGTGAGTTCTACGGGTACAT-3' \\
& Reverse 5'- TCAGGGTGTATTCATCCAGCG-3' \\
CD47 & Forward 5'- AGAAGGTGAAACGATCATCGAGC-3 \\
& Reverse 5' - CTCATCCATACCACCGGATCT-3' \\
CHD9 & Forward 5'- AAGTGGAATCTCAAACTGAGCC-3' \\
& Reverse 5'- GATGCGAAGTAAACTGCCGAT-3' \\
CUL3 & Forward 5'- AATGCTTGCCAGATGTTA-3' \\
& Reverse 5'- TTGGTTCTTCCGTTGATT -3' \\
\hline
\end{tabular}

Quantitative RT-PCR was performed to determine the mRNA expression levels of ATNX1, IRS2, CD47, CHD9 and CUL3, GAPDH was used as an endogenous control. All the primer sequences were shown in Table 1.

\section{Protein analysis}

For western blot, total proteins were extracted from tissues or cultured cells using RIPA buffer containing protease inhibitors cOmplete, ULTRA, Mini, EDTA-free, EASYpack (Roche, Basel, Switzerland), while the membrane protein were extracted by ProteoExtract ${ }^{\circledR}$ Transmembrane Protein Extraction Kit (Merck KGaA, Darmstadt, Germany). Protein concentrations were determined by BCA method. Primary polyclonal antibodies were purchased from Santa Cruz (Santa Cruz Biotechnology, CA, USA): CD47 antibody (SC7057), CUL3 antibody (SC8556). The secondary antibodies were anti-goat HRP-linked. The blots were developed using ECL reagent (Millpore, MASS, USA). GAPDH antibody was used as an endogenous control. The integrated density of the band was quantified by Image J software. All experiments were repeated at least three times.

\section{Bisulfite Sequencing}

Genomic DNA was isolated from samples of patients with HSCR and controls. The DNA samples were treated and modified with a sodium bisulfite procedure using the EZ DNA Methylation-Gold ${ }^{\mathrm{TM}}$ Kit (QIAGEN, Valencia, CA), according to manufacturer's instructions. DNA methylation of miR-141 was analyzed using bisulfite sequencing PCR method. DNA was amplified in 40 cycles for $1 \mathrm{~min}$ at $95^{\circ} \mathrm{C}, 1 \mathrm{~min}$ at $58.8^{\circ} \mathrm{C}$, and $1 \mathrm{~min}$ at $72^{\circ} \mathrm{C}$ followed by a final extension at $72^{\circ} \mathrm{C}$ for $10 \mathrm{~min}$. Amplified products were purified with the TIANquick Midi Purification Kit (QIAGEN, Valencia, CA) and cloned into the pCR2.1 vector (Invitrogen Life Technologies Co, CA, USA), and individual clones were sequenced using M13 reverse primer and an automated ABI Prism 3730xl Genetic Analyser (Applied Biosystems, CA, USA). Approximately 10 different clones from each PCR product were sequenced to characterize the methylation status of the CpG sites.

\section{Cell culture and transfections}

Human 293T and SH-SY5Y cell were obtained from American Type Culture Collection (ATCC, Manassas VA, USA), which were cultured in complete growth medium (Hyclone, UT, USA), supplemented with $10 \%$ fetal bovine serum (10\%FBS), $100 \mathrm{U} / \mathrm{mL}$ penicillin, and $100 \mu \mathrm{g} / \mathrm{mL}$ streptomycin at $37^{\circ} \mathrm{C}, 5 \% \mathrm{CO}_{2}$. Synthetic miRNA molecules of miR-141 mimics, inhibitor, normal control and siRNA of CD47/CUL3 (GenePharma, Shanghai, China) were used in transfection experiments. Cells were cultured to about $50 \%$ confluence before transfected, using Lipofectamine 2000 (Invitrogen Corp, CA, USA).

Dual-luciferase reporter assay

The 3'-UTR sequence of CD47 and CUL3 predicted to interact with miR-141 and the mutated sequence were inserted into the KpnI and SacI sites of pGL3 promoter vector (Genscript, Nanjing, China). These constructs were named pGL3-CD47, pGL3-CUL3, pGL3-CD47-mut and pGL3-CUL3-mut. A Renilla luciferase 


\section{Cellular Physiology Cell Physiol Biochem 2013;32:1655-1667 \begin{tabular}{ll|l} 
and Biochemistry & $\begin{array}{l}\text { DOI: 10.1159/000356601 } \\
\text { Publisned online: December 05, } 2013\end{array}$ & $\begin{array}{l}\text { ( 2 2013 S. Karger AG, Basel } \\
\text { www.karger.com/cpb }\end{array}$ \\
\hline
\end{tabular}}

Tang et al.: miR-141 in Hirschsprung's Disease

Table 2. Bioinformatics: Predict potential targets of miR-141

\begin{tabular}{llcccc}
\hline microRNA & Related Gene & miRGen & PicTar & Target Scan & miRecords \\
\hline hsa-miR-141 & IRS2 & $\sqrt{ }$ & & & $\sqrt{ }$ \\
& CD47 & $\sqrt{ }$ & $\sqrt{ }$ & $\sqrt{ }$ & $\sqrt{ }$ \\
& ATNX1 & & & $\sqrt{ }$ & $\sqrt{ }$ \\
& CUL3 & $\sqrt{ }$ & $\sqrt{ }$ & $\sqrt{ }$ & $\sqrt{ }$ \\
& CHD9 & $\sqrt{ }$ & & $\sqrt{ }$ & \\
\hline
\end{tabular}

vector pRL-SV40 (5ng) was also co-transfected to normalize the differences in transfection efficiency. After transfection for $48 \mathrm{~h}$, cells were harvested and assayed with Dual-Luciferase Reporter Assay System (Promega, WI, USA) according to the manufacturer's instructions. Experiment was repeated three times in triplicate.

Cell transwell assays

Cells were cultured in six-well plates and transfected with miR-141 inhibitor, siRNA of CD47/CUL3 and normal control. After transfection for $48 \mathrm{~h}$, cells were seeded at $1 \times 10^{6} \mathrm{cells} / \mathrm{ml}$ with serum-free medium, $100 \mu \mathrm{l}$ cell suspension was seeded to the upper chamber of an $8.0-\mu \mathrm{m}$-pore membrane chamber (Millpore, MASS, USA) in a special adapted 24-well plates, lower chamber was filled with $600 \mu \mathrm{l}$ DMEM with $10 \%$ FBS. After cultured for 24 hours, cells were stained with crystal violet staining solution (Beyotime, Nantong, China) for $15 \mathrm{~min}$, then counted and photographed under $40 \times$ magnification (five views each well). All experiments were performed in triplicate.

Cell proliferation assays

To investigate the effect of miR-141 inhibitor in cell proliferation, cells lines were transfected with miR-141 inhibitor, siRNA of CD47/CUL3 compared with the normal control. Cell growth was determined by tetrazolium salt cell proliferation assay kit. Cells were plated at $1 \times 10^{4}$ cells per well into 96 -well plate after transfected for 48 hours, and was incubated at $37^{\circ} \mathrm{C}$ for 4 hours. Then, $150 \mu \mathrm{L}$ of dimethylsulfoxide was added to each well. Absorbance at $490 \mathrm{~nm}$ was determined by the TECAN infinite M200 Multimode microplate reader (Tecan, Mechelen, Belgium). Each assay was performed intriplicate and repeated 3 times independently.

\section{Cell cycle and apoptosis analysis}

Cells were transfected with miR-141 inhibitor, as well as normal controls and were harvested after transfected for $48 \mathrm{~h}$. For the cell cycle assay, cells were fixed in $75 \%$ alcohol, and stained with propidium iodide (Sigma, MO, USA). For the apoptosis analysis, cells were washed in PBS, and then mixed with Annexin V-FITC Apoptosis Detection Kit (BD Biopharmingen, NJ, USA) for 15 min in the dark. All experiments were analyzed by BD Biasciences FACS Calibur Flow Cytometry (BD Biasciences, NJ, USA). The tests were repeated for three times with triplicate per experiment.

\section{Statistical analysis}

Statistical analysis was performed using STATA9.2, and presented with Graphpad prism software. Experimental data of tissue samples were presented as box plot of the median and range of log-transformed relative expression level which was analyzed by Wilcoxon rank-sum (Mann-Whitney) test. The top and bottom of the box represented the seventy-fifth and twenty-fifth percentile. The whiskers indicated the 10 th and 90th points. While the results obtained from experiment in vitro assays was presented as mean \pm SEM from three separate experiments in triplicates per experiment, and the data was analyzed by doublesided Student's t-test. Pearson correlation analysis was used to analyze the relationship of expression level of tissues between case and control group. Results were considered statistically significant at $\mathrm{P}<0.05$. 


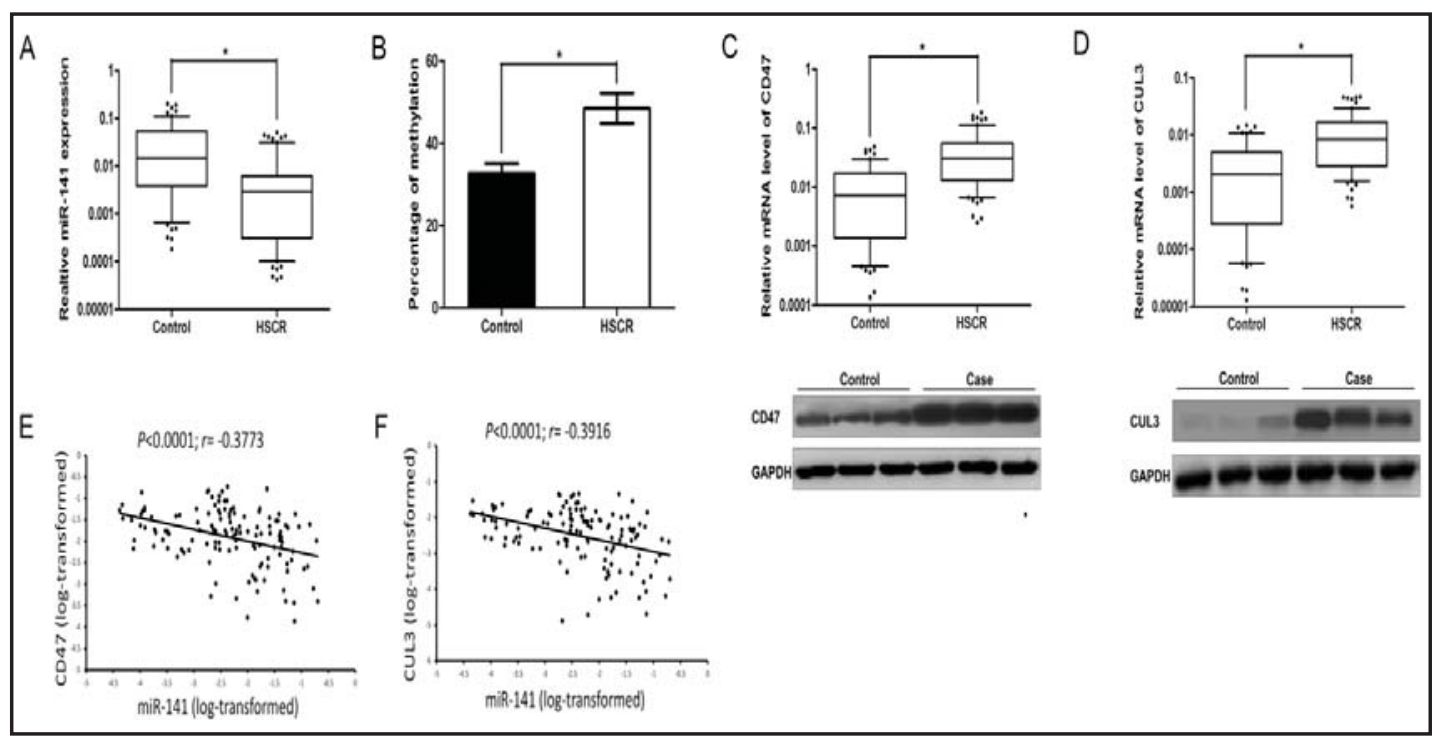

Fig. 1. MiR-141 was down-regulated and hypermethylation whereas CD47/CUL3 were up-regulated in HSCR patients. A: The relative expression levels of miR-141 in human HSCR tissues $(n=70)$ and control tissues $(n=60)$ were evaluated by qRT-PCR. Data were presented as box plot of the median and range of log-transformed relative expression levels. The top and bottom of the box represent the seventy-fifth and twenty-fifth percentile. The whiskers indicate the 10th and 90th points. * Significantly different compared with that of control $(\mathrm{P}<0.05)$. B: The hypermethylation status of miR-141 in HSCR samples. C-D: The expression levels of CD47 and CUL3 in mRNA (up panel) and protein (low panel) levels in HSCR patients and controls. E-F: The inverse correlation between miR-141 and CD47/CUL3 expression levels. Data were analyzed using the Pearson correlation analysis with natural log-transformed. For CD47: $r=-.3773, \mathrm{P}<.0001$; for CUL3: $\mathrm{r}=-.3916, \mathrm{P}<.0001$.

\section{Results}

Results of clinical sample information analysis

The clinical information, including age, gender (Male/Female) and body weight, was obtained from participants both HSCR patients and normal controls. The result of age of HSCR and control group was $4.01 \pm 0.30$ months old and $3.54 \pm 0.27$ months old, while the body weight was $5.6 \pm 0.32 \mathrm{~kg}$ and $5.2 \pm 0.26 \mathrm{~kg}$, both of which was no difference statistically. Besides, the gender rate (Male/Female) of HSCR and control was 57/13 and 49/11, which matched the gender rate of this disease.

Bioinformatics: Predict potential targeting genes of miR-141

To predict potential target genes of miR-141, bioinformatics methods were used. We applied three different databases to predict genes which are potential regulated by miR141. Five genes with the highest score presented in all the software above were selected as candidate genes including IRS2, CD47, ATXN1, CUL3 and CHD9 (Table 2).

MiR-141 was down-regulated in colon tissues of HSCR patients induced by hypermethylation

TaqMan qRT-PCR was used to detect the relative expression levels of miR-141 in different groups which was normalized to the levels of snRNA-U6. The expression levels of miR-141 in HSCR colon samples were significantly lower than the control samples $\left(\mathrm{P}=4.04 \times 10^{-7}\right)$ (Fig. 1A). Besides, methylation status of a CPG island in the promoter region of miR-141 gene by using the BSP method indicated a hypermethylation status in 70 human colon tissues of HSCR patients compared with 60 controls tissues $\left(\mathrm{P}=7.1 \times 10^{-3}\right)$ (Fig. 1B). The methylation status of samples is shown in Figure 2. 


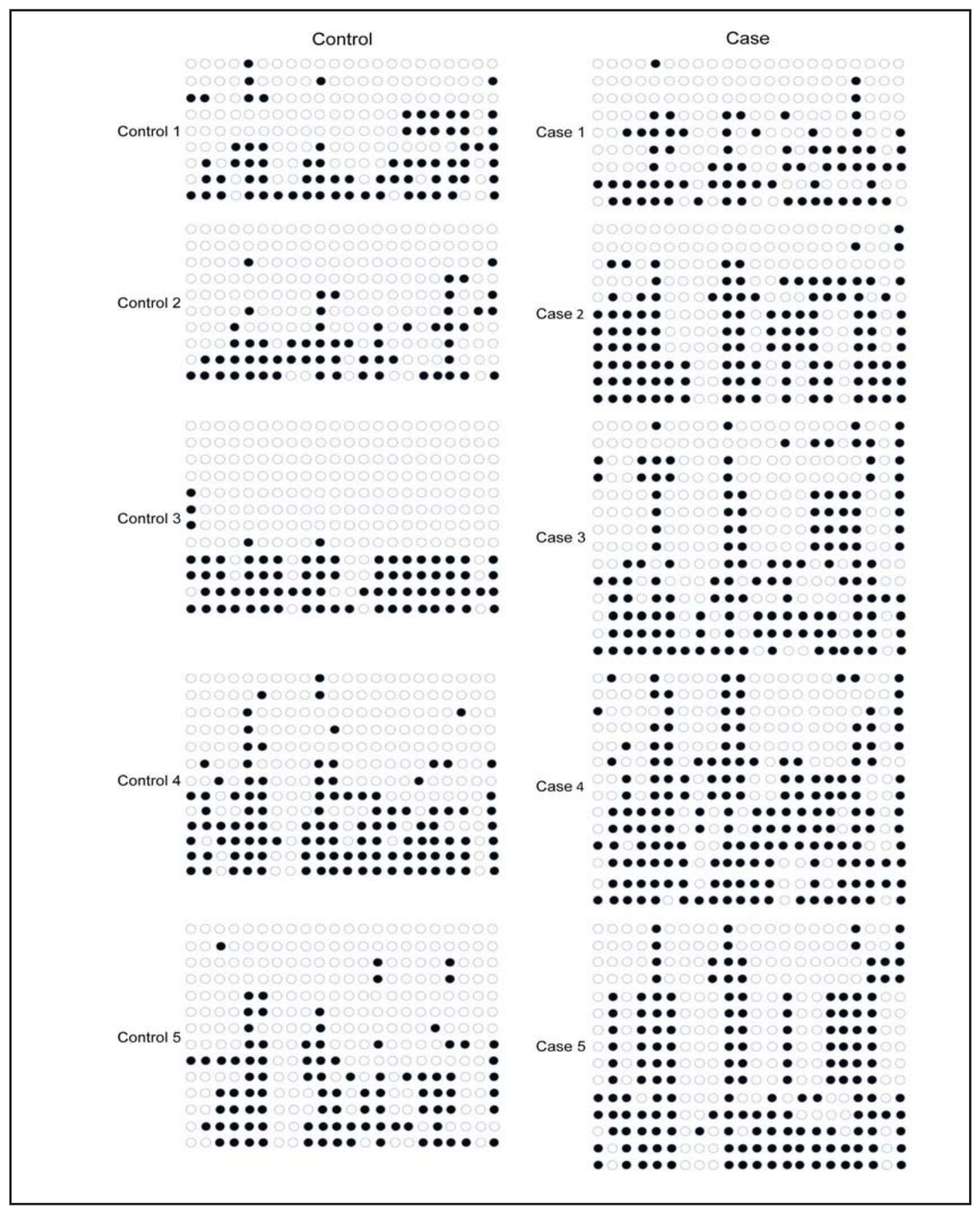

Fig. 2. Results of bisulfite sequencing of miR-141 CpG Island in colon tissues of HSCR patients and controls. Filled and open circles represent methylated and unmethylated CpGs, respectively.

CD47 and CUL3 were up-regulated in colon tissues of HSCR patients

To detecte whether these candidate genes were involved in HSCR, TaqMan qRT-PCR methods were used to examine the expression level of these candidate genes. $C D 47$ expression levels in 70 HSCR samples were higher than those in the 60 control samples $\left(\mathrm{P}=8.19 \times 10^{-10}\right)$ (Fig. 1C) as well as CUL3 ( $\left.\mathrm{P}=3.10 \times 10^{-9}\right)$ (Fig. 1D). However, the expression levels of ATNX1, IRS2 and CHD 9 showed no significant difference in two groups. We further tested the protein levels of CD47 and CUL3, and found that the protein levels of CD47 and CUL3 were consistent with their mRNA expression levels (Fig. 1C, D). Quantization of Western-blotting was done 


\section{Cellular Physiology Cell Physiol Biochem 2013;32:1655-1667 \begin{tabular}{ll|l} 
and Biochemistry & $\begin{array}{l}\text { DOI: 10.1159/000356601 } \\
\text { Published online: December 05, } 2013\end{array}$ & $\begin{array}{l}\text { c 2013 S. Karger AG, Basel } \\
\text { www.karger.com/cpb }\end{array}$ \\
\hline
\end{tabular} Tang et al.: miR-141 in Hirschsprung's Disease}

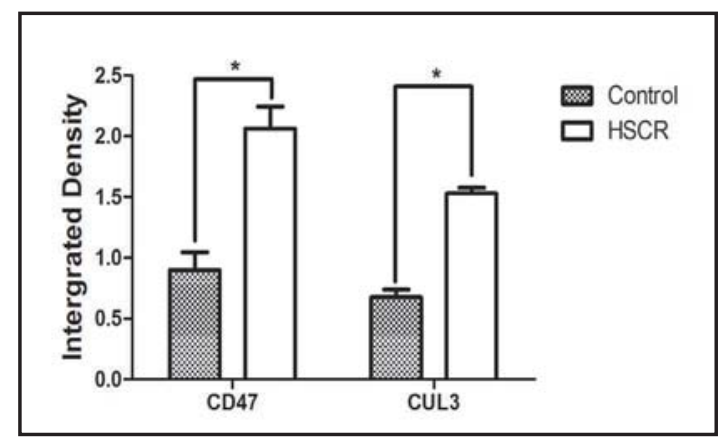

Fig. 3. The intergrated density of CD47 and CUL3 protein in HSCR samples and controls.

by Image J software, for CD47 and CUL3, integrated density of HSCR samples was higher than controls, for CD47, $P=7.0 \times 10^{-3}$, for CUL3, $\mathrm{P}=4.0 \times 10^{-4}$ (Fig. 3).

\section{Correlation analysis of miR-141 and CD47/CUL3}

We further analyzed the correlation between miR-141 and CD47/CUL3 with the relative expression level of miRNA or mRNA in cases and controls by using Pearson correlation analysis. Significantly increased levels of CD47 and CUL3 were observed in subjects with decreased levels of miR-141, results for CD47: $\mathrm{P}<0.001, \mathrm{r}=-0.3773$; results for CUL3: $\mathrm{P}<0.001$, $\mathrm{r}=-0.3916$ (Fig.1E, F).

MiR-141 negative regulated CD47/CUL3 in cell lines

To verify whether CD47 and CUL3 are two target genes of miR-141, we performed the miRNA luciferase reporter assay. We constructed both the wild type and mutant type luciferase reporter plasmids with the binding region of 3'-UTR of CD47 and CUL3 mRNA (Fig. 4A). By co-transfecting miR-141 mimics, control and wild type or mutant type luciferase reporter plasmids into $293 \mathrm{~T}$ and SH-SY5Y cells, we found that significantly decreased luciferase activity in cell lines co-transfected miR-141 mimics and pGL3-CD47 or pGL3-CUL3, as compared with the control (Fig. 4B). The result illustrated that miR-141 regulated CD 47 or CUL3 by combining to the 3'-UTR of mRNA. Each experiment was conducted three times in triplicates. Besides, in order to detect the alternation of expression level of CD47/CUL3, we further transfected miR-141 inhibitor into 293T and SH-SY5Y cell lines. As expected, the results showed that the mRNA and protein levels of CD47 and CUL3 were increased in cell lines transfected with miR-141 inhibitor (Fig. 4C, D).

Decreased level of miR-141 inhibited cell migration and cell proliferation without affecting cell apoptosis and cell cycle progression

After transfecting miR-141 inhibitor into 293T and SH-SY5Y cell lines, we conducted cell migration assay. The result showed the number of migrated cells transfected with miR141 inhibitor was significantly fewer when compared with the normal control (Fig. 5A). The number of migrated cells of each image was numbered artificially. Migration of normal control group was normalized to 1 .

By using MTT assay, cells proliferation ability was measured after transfecting with miR-141 inhibitor and normal control in 293T and SH-SY5Y cell lines. As showed in Figure $5 \mathrm{~B}$, cell proliferation was suppressed with the reduction of miR-141.

We also conducted the experiment by using flow cytometry analysis to investigate whether miR-141 is involved in the apoptosis and cell cycle progression. We found that the percentage of apoptosis cells was no difference between cells transfected with miR-141 inhibitor and normal control. Similarly, miR-141 inhibitor did not affect cell cycle progression when compared with normal control (Fig. 6). 

Cellular Physiology Cell Physiol Biochem 2013;32:1655-1667 \begin{tabular}{|l|l|l}
\hline DOI: 10.1159/000356601 & (c) 013 S. Karger AG, Basel
\end{tabular} \begin{tabular}{l|l} 
and Biochemistry Publisnea onine: December 05, 2013 & www.karger.com/cpb
\end{tabular}

A

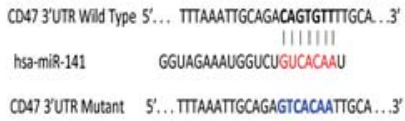

B

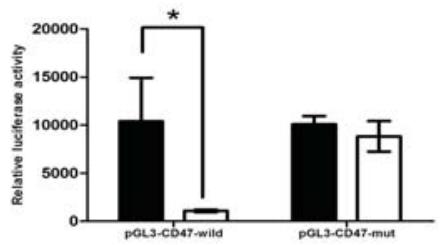

293T cell line

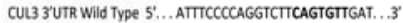

hsa-miR-141 GGUAGAAAUGGUCUGUCACAAU

CUL3 3'UTR MUtant $\quad 5^{\prime}$... ATTTCCCCAGGTCTIGTCACAAGAT ... 3'

SH-SY5Y cell line

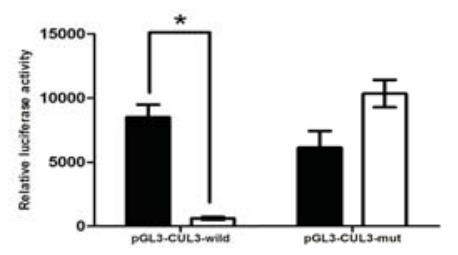

Control miR-141 mimics
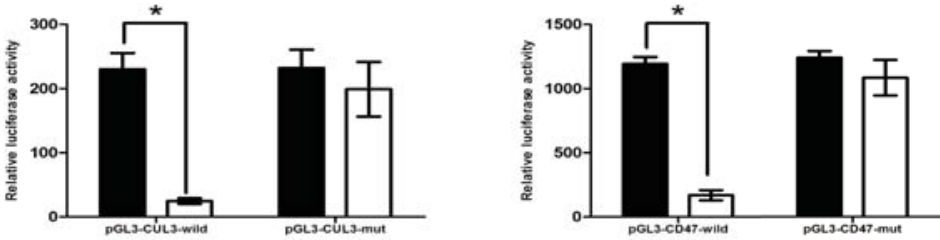

C
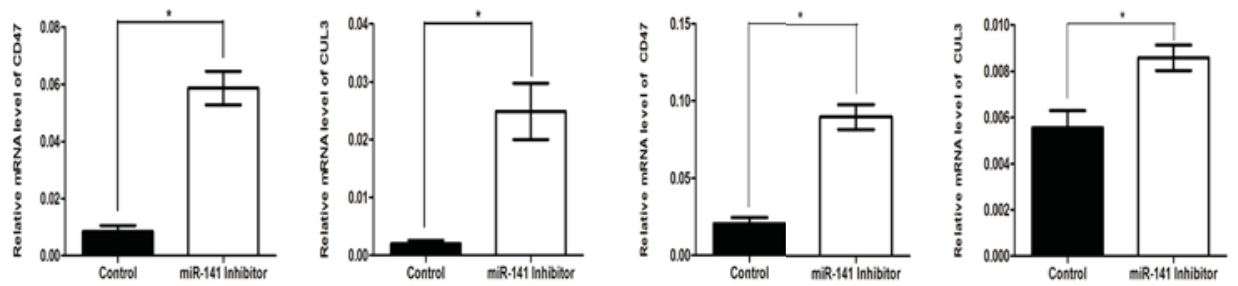

D

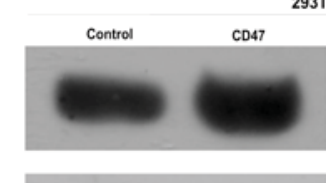

Control CUL3
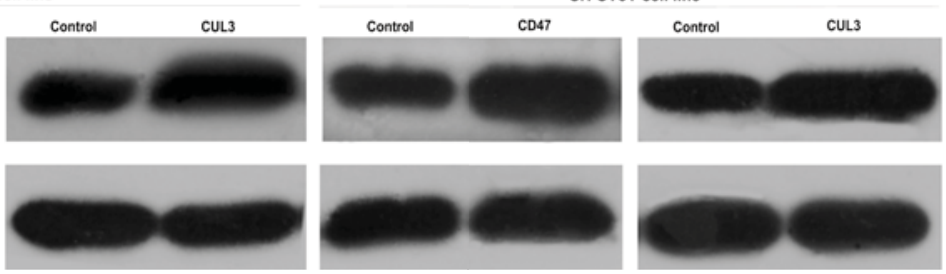

Fig. 4. The reduction of miR-141 increased CD47 and CUL3 in cell lines. A: The sequence of the binding site of CD47/CUL3 wild type with miR-141 and the mutant type of CD47/CUL3 in 3'UTR. B: The results of luciferase reporter assay. 293T and SH-SY5Y and SH-SY5Y cell lines were co-transfected with miR-141 mimics or miR-control, renilla luciferase vector pRL-SV40 and CD47 or CUL3 3'UTR luciferase reporters for 48h. Both firefly and Renilla luciferase activities are measured in the same sample. Firefly luciferase signals were normalized with Renilla luciferase signals. All tests were performed in triplicate and presented as mean \pm SEM. C, D: The mRNA and protein expression levels of CD47 and CUL3 in 293T and SH-SY5Y cell lines after transfection with miR-141 inhibitor were obviously higher than in cells transfection with inhibitor NC. Data were presented as mean \pm SEM from three separate experiments performed in triplicates, and were analyzed by double-sided Student's t-test. (* indicates $\mathrm{P}<0.05)$.

The suppression of cell migration and proliferation were reversed by co-transfecting miR141 inhibitor and CD47/CUL3 SiRNA

By co-transfecting miR-141 inhibitor and CD47/CUL3 siRNA in 293T and SH-SY5Y cell lines, we found that the abilities of migration and proliferation of cells co-transfected with miR-141 inhibitor and CD47 siRNA or CUL3 siRNA were partly restored, and the abilities of migration and proliferation of cells co-transfected with miR-141 inhibitor and CD47/CUL3 


\section{Cellular Physiology Cell Physiol Biochem 2013;32:1655-1667

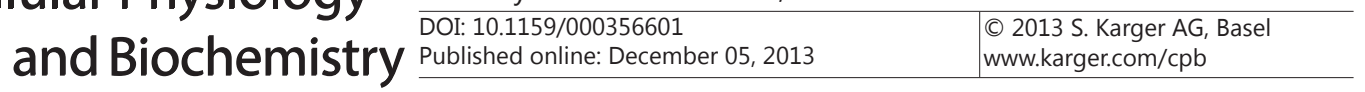

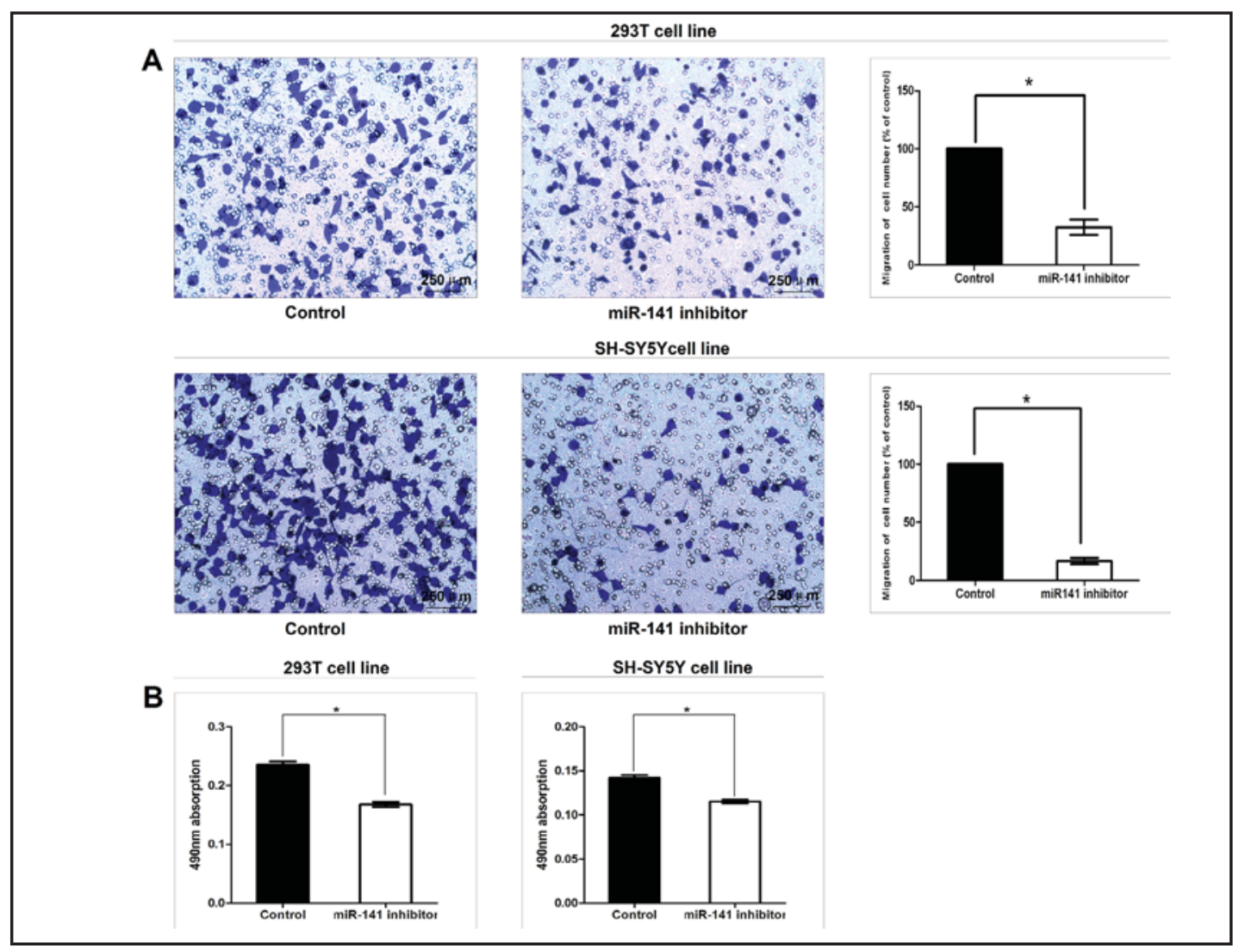

Fig. 5. The reduction of miR-141 inhibited cell migration and cell proliferation. The cells were transfected with miR-141 inhibitor and normal control to assay cell migration and proliferation by transwell assay and MTT assay. A: The representative images of migration cells at the bottom of the membrane stained with crystal violet were visualized as shown (left panel). The quantifications of cell migration were presented as percentage migrated cell numbers and the integrated intensity of migrated cells (right panel).B: The results of MTT assay. Data were presented as mean \pm SEM of $490 \mathrm{~nm}$ absorption. * indicates significant difference compared with control group (* indicates $\mathrm{P}<0.05$ ).

siRNA were much more restored. Migration ability of cells transfected CD47 siRNA or CUL3 siRNA exhibited normal migration when compared to the control (Fig. 7).

\section{Discussion}

In the study, we first predict the potential target genes of miR-141 by miRGen, Pictar and TargetScan database. Then we detected the expression levels of miR-141 and its potential target genes in HSCR samples and controls, and found that the miR-141 were down-regulated whereas CD47/CUL3 were up-regulated in HSCR tissues. Furthermore, the negative correlations between the expression levels of CD47/ CUL3 and miR-141 indicated that the negative regulation relationship between miR-141 and CD47/CUL3 in HSCR. In order to explore why miR-141 was lower expression in HSCR tissues, we tested methylation level of miR-141 gene, an epigenetic modification. Epigenetic modification is some mechanisms which regulate gene activity and functions without altering the DNA sequence, and the common mechanisms including DNA methylation, histone modifications and non-coding RNA regulation. Epigenetic modification frequently participates in a variety of diseases [9-11]. DNA methylation, as a major modification of epigenetic modification, broadly participated in human development process and a variety of diseases. Abnormal 


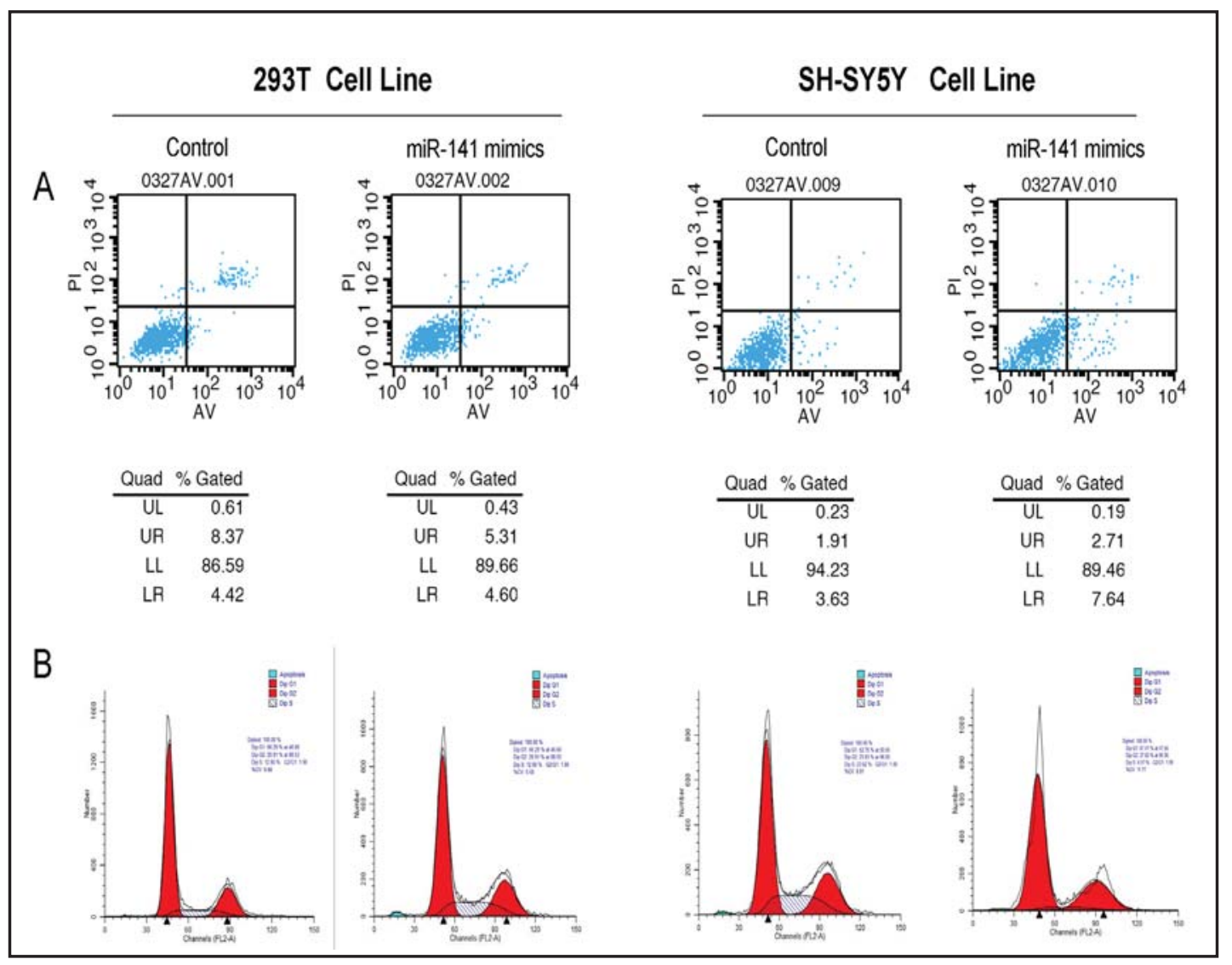

Fig. 6. MiR-141 inhibitor didn't affect cell apoptosis and cycle. Flow cytometry assay was performed to assess cell apoptosis and cell cycle. Both of the two assays indicated no significant difference between cells treated with miR-141 inhibitor and normal control. A: cell apoptosis assay. B: cell cycle assay.

DNA methylation is considered to be a hallmark of human tumors [12]. Abnormal DNA methylation was found closely related to human life processes such as diet [13], infertility [14]. DNA methylation is also involved in the regulation of miRNAs. Aberrant methylation of a CpG island located in the promoter region of miR-141 gene in invasive breast cancer cells and other cancer cells have been reported [15].

To detect whether miR-141 participated in the process of HSCR through the miR-141CD47/CUL3 pathway, we conducted the experiment in vitro. To determine the functional relevance of miR-141, we performed cell proliferation assay and migration assay in vitro. Our results showed that miR-141 inhibited cell proliferation and migration via directly targeting CD47 and CUL3. CD47 is a ubiquitous five-spanning membrane multi-faceted receptor that belongs to the immunoglobulin superfamily, and has been reported to be involved in many and diverse cellular processes, including apoptosis, proliferation, adhesion and migration [16]. Previous studies have documented a role for CD47 in migration of multiple cell types, including neutrophils, endothelial cells, and smooth muscle cells [17]. In addition to its expression in other extraneural tissues, CD47 was known to be expressed in the brain, and its expression has been reported to be associated with memory formation in rat model [18]. CUL3, a Cullin family scaffold protein, was reported to control early embryonic development in several genetic models through mechanisms not understood [19]. It was reported that dysfunction of the Cul3/BACURD complex decreases cell migration potential and impairs RhoA-mediated convergent extension movements during Xenopus gastrulation [20]. All the information supported our result that CD47/CUL3 participated in cell processes, especially in cell migration. By cutting down the expression of CD47 and CUL3 could be reversed. 

Cellular Physiology Cell Physiol Biochem 2013;32:1655-1667 \begin{tabular}{l|l}
\hline DOI: 10.1159/000356601 & O) 2013 S. Karger AG, Basel
\end{tabular} and Biochemistry Published online: December 05, 2013 www.karger.com/cpb

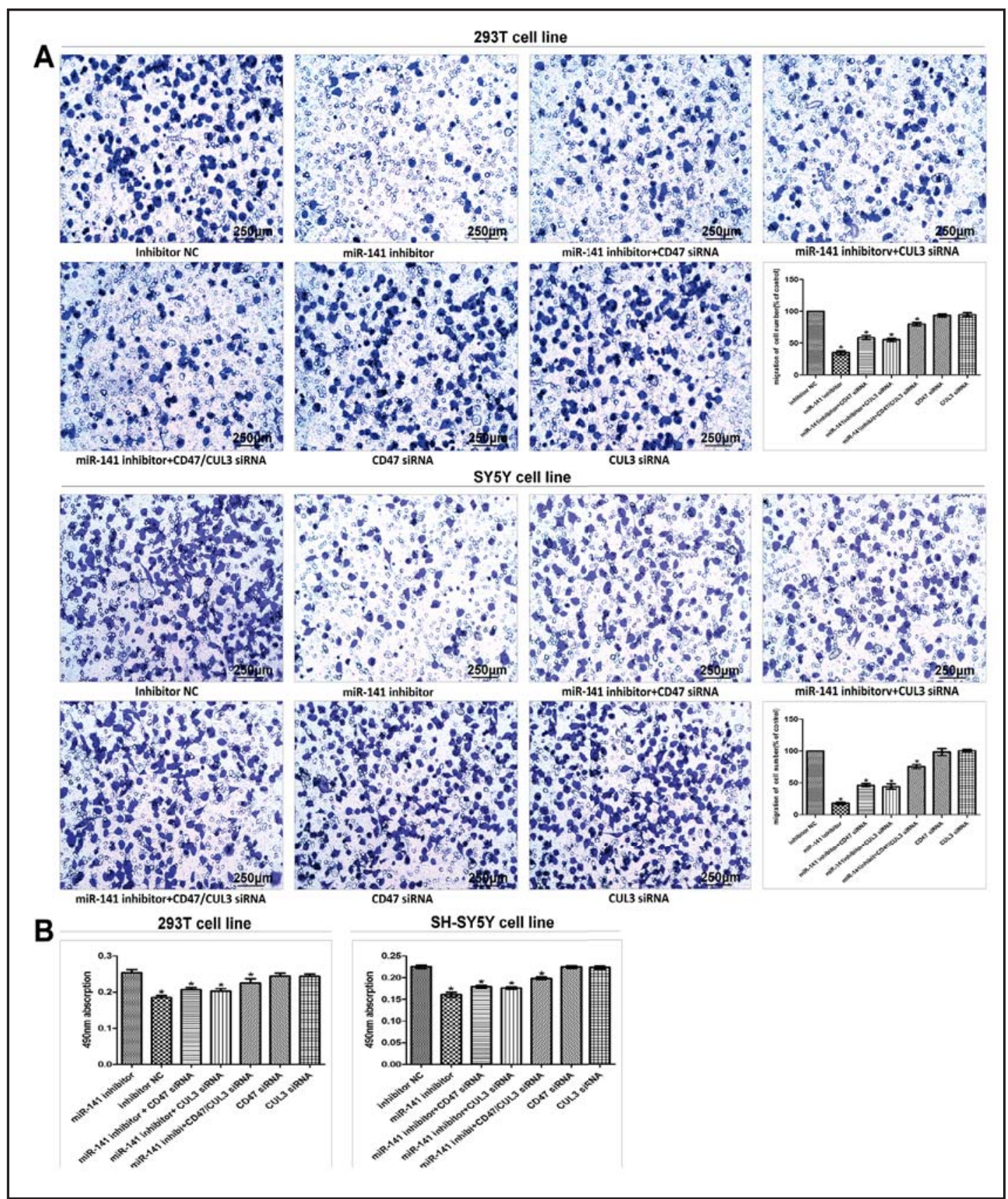

Fig. 7. Migration and proliferation ability were reversed by the decreased level of CD47/CUL3. Cells were divided into six groups: cell transfected with inhibitor NC; cell transfected with miR-141 inhibitor; cell cotransfected with miR-141 inhibitor and CD47 siRNA; cell co-transfected with miR-141 inhibitor and CUL3 siRNA; cell transfected with CD47 siRNA; cell transfected with CUL3 siRNA. We compared the co-transfection group with others in order to detect the reversed affection. Migration and proliferation were partly reversed after co-transfected with miR-141 and CD47 or CUL3 siRNA when compared with the cells transfected with miR-141, and were much more restored after co-transfected with miR-141 and CD47/CUL3 siRNA. Data were presented as mean \pm SEM from three separate experiments performed in triplicates, and were analyzed by double-sided Student's t-test. ( ${ }^{*}$ indicates $\left.\mathrm{P}<0.05\right)$.

Based on all the results in vitro, we speculate miR-141 indeed inhibited cells migration and proliferation through up-regulated CD47 and CUL3. 


\section{Cellular Physiology Cell Physiol Biochem 2013;32:1655-1667 \begin{tabular}{ll|l} 
and Biochemistry & $\begin{array}{l}\text { DOI: 10.1159/000356601 } \\
\text { Published online: December 05, } 2013\end{array}$ & $\begin{array}{l}\text { C 2013 S. Karger AG, Basel } \\
\text { www.karger.com/cpb }\end{array}$ \\
\hline
\end{tabular}}

Tang et al.: miR-141 in Hirschsprung's Disease

In conclusion, we speculate that during enteric nervous system development, hypermethylation in miR-141 gene reduced the expression of miR-141, and resulted in the over-expression of CD47 and CUL3. This mechanism induced the suppression of cell migration and proliferation, thus may result in the failure of ENCCs to reach the distal intestine in the specific period. The miR-141-CD47/CUL3 pathway might bring us a novel direction in the mechanism of neural crest cell migration stasis which was the main etiology of HSCR. The crucial role of miRNAs might be a remarkable finding in HSCR. These findings may provide new targets via miR-141 and methylation in diagnosis and therapy of HSCR in the future.

\section{Conflict of Interest}

There are no conflicts of interest.

\section{Acknowledgements}

We thank Dr. Jie Zhang, HuanChen, Xiaofeng Lv, Changgui Lu, Weiwei Jiang, Wei Li (Nanjing Children's Hospital Affiliated to Nanjing Medical University) for sample collection.

This work was supported by Grants: Nanjing Medical Science and Technique Development Foundation [NMSTDF 201108010], Priority Academic Program Development of Jiangsu Higher Education Institutions, Natural Science Foundation of China [NSFC 81370473].

\section{References}

1 Spiegel JC, Lorenzen JM, Thum T: Role of microRNAs in immunity and organ transplantation. Expert Rev Mol Med 2011;13:e37.

-2 Lee ST, Chu K, Oh HJ, Im WS, Lim JY, Kim SK, Park CK, Jung KH, Lee SK, Kim M, Roh JK: Let-7 microRNA inhibits the proliferation of human glioblastoma cells. J Neurooncol 2011;102:19-24.

- 3 Du Y, Xu Y, Ding L, Yao H, Yu H, Zhou T, Si J: Down-regulation of miR-141 in gastric cancer and its involvement in cell growth. J Gastroenterol 2009;44:556-561.

4 Hu W, Wang X, Ding X, Li Y, Zhang X, Xie P, Yang J, Wang S: MicroRNA-141 represses HBV replication by targeting PPARA. PLoS One 2012;7:e34165.

5 Pan ZW, Li JC: Advances in molecular genetics of Hirschsprung's disease. Anat Rec (Hoboken) 2012;295:1628-1638.

-6 Emison ES, McCallion AS, Kashuk CS, Bush RT, Grice E, Lin S, Portnoy ME, Cutler DJ, Green ED, Chakravarti A: A common sex-dependent mutation in a RET enhancer underlies Hirschsprung disease risk. Nature 2005;434:857-863.

7 Parisi MA, Kapur RP: Genetics of Hirschsprung disease. Curr Opin Pediatr 2000;12:610-617.

8 Garcia-Barcelo MM, Tang CS, Ngan ES, Lui VC, Chen Y, So MT, Leon TY, Miao XP, Shum CK, Liu FQ Yeung MY, Yuan ZW, Guo WH, Liu L, Sun XB, Huang LM, Tou JF, Song YQ Chan D, Cheung KM, Wong KK, Cherny SS, Sham PC, Tam PK: Genome-wide association study identifies NRG1 as a susceptibility locus for Hirschsprung's disease. Proc Natl Acad Sci U S A 2009;106:2694-2699.

-9 Handel AE, Ebers GC, Ramagopalan SV: Epigenetics: molecular mechanisms and implications for disease. Trends Mol Med 2010;16:7-16.

10 Dallosso AR, Hancock AL, Szemes M, Moorwood K, Chilukamarri L, Tsai HH, Sarkar A, Barasch J, Vuononvirta R, Jones C, Pritchard-Jones K, Royer-Pokora B, Lee SB, Owen C, Malik S, Feng Y, Frank M, Ward A, Brown KW, Malik K: Frequent long-range epigenetic silencing of protocadherin gene clusters on chromosome 5q31 in Wilms' tumor. PLoS Genet 2009;5:e1000745. 


\section{Cellular Physiology Cell Physiol Biochem 2013;32:1655-1667 and Biochemistry \begin{tabular}{l|l} 
DOI: 10.1159/000356601 \\
Publisned onlne: December 05, 2013 & $\begin{array}{l}\text { O 2013 S. Karger AG, Basel } \\
\text { www.karger.com/cpb }\end{array}$ \\
\cline { 2 - 3 }
\end{tabular}}

Tang et al.: miR-141 in Hirschsprung's Disease

-11 Schuebel KE, Chen W, Cope L, Glockner SC, Suzuki H, Yi JM, Chan TA, Van Neste L, Van Criekinge W, van den Bosch S, van Engeland M, Ting AH, Jair K, Yu W, Toyota M, Imai K, Ahuja N, Herman JG, Baylin SB: Comparing the DNA hypermethylome with gene mutations in human colorectal cancer. PLoS Genet 2007;3:1709-1723.

12 Cusack M, Scotting P: DNA methylation in germ cell tumour aetiology: current understanding and outstanding questions. Reproduction 2013;146:R49-60.

13 Glier MB, Green TJ, Devlin AM: Methyl nutrients, DNA methylation, and cardiovascular disease. Mol Nutr Food Res 2013, doi: 10.1002/mnfr.201200636.

14 Wu W, Shen O, Qin Y, Niu X, Lu C, Xia Y, Song L, Wang S, Wang X: Idiopathic male infertility is strongly associated with aberrant promoter methylation of methylenetetrahydrofolate reductase (MTHFR). PLoS One 2010;5:e13884.

-15 Vrba L, Jensen TJ, Garbe JC, Heimark RL, Cress AE, Dickinson S, Stampfer MR, Futscher BW: Role for DNA methylation in the regulation of miR-200c and miR-141 expression in normal and cancer cells. PLoS One 2010;5:e8697.

16 Sick E, Jeanne A, Schneider C, Dedieu S, Takeda K, Martiny L: CD47 update: a multifaceted actor in the tumour microenvironment of potential therapeutic interest. Br J Pharmacol 2012:167:1415-1430.

17 Rebres RA, Kajihara K, Brown EJ: Novel CD47-dependent intercellular adhesion modulates cell migration. J Cell Physiol 2005;205:182-193.

18 Huang AM, Wang HL, Tang YP, Lee EH: Expression of integrin-associated protein gene associated with memory formation in rats. J Neurosci 1998;18:4305-4313.

19 Chen Y, Yang Z, Meng M, Zhao Y, Dong N, Yan H, Liu L, Ding M, Peng HB, Shao F: Cullin mediates degradation of RhoA through evolutionarily conserved BTB adaptors to control actin cytoskeleton structure and cell movement. Mol Cell 2009;35:841-855.

20 Vega Hernandez L, Castano Gonzalez L, Belar Beitia O, Ruiz Aja E, Martinez Ezquerra N, Lopez AlvarezBuhilla P: Study of polymorphisms associated to Hirschsprung's disease. Cir Pediatr 2011;24:131-136. 